\title{
Una carta del Factor de Potosí: Contribución al estudio de la temprana historia colonial de los Andes Meridionales ${ }^{1}$
}

José María Casassas y Drahomira SRYtrová

\section{Introducción}

Los diversos especialistas sobre el conocimiento de la sociedad andina en el momento en que recibe el impacto de la ocupación europea continúan en la búsqueda de fuentes escritas, pertenecientes al siglo XVI. No cabe duda que estas tempranas informaciones ofrecen un conocimiento de primera mano para comprender no sólo el móvil de la ocupación española, sino, y fundamentalmente, nos entregan una imagen, a veces detallada, de la sociedad andina. Los estudios de esta materia normalmente se enfrentan a fuentes históricas literarias, como las crónicas, que si bien describen particularidades del mundo andino, no logran profundizar situaciones no bien esclarecidas en la documentación oficial. Por esto es que especialmente los etnohistoriadores no dejan de buscar documentación, que bajo un carácter administrativo, y a veces burocrático, encierran una información de profundo contenido socioeconómico. Las visitas realizadas y escritas por las autoridades políticas y administrativas, los censos tempranos, los libros eclesiásticos y tantas otras variables similares se utilizan para conocer la organización misma de la sociedad andina, cuyo estudio, por su carácter ágrafo, debe apoyarse en este tipo de documentación. La carta del Factor de Potosí es parte de este contexto. Se trata de un documento notable, escrito por el Factor de Potosí, Juan Lozano Machuca, "en que da cuenta de cosas de aquella villa y de las minas de los Lipes y de Atacama". Como se trata de un documento escrito en el año 1581, debe tenerse en cuenta que las informaciones recogidas en el terreno fueron aportadas por indígenas que habían formado parte de la administración incaica. Por otro lado, tanto el Factor de Potosí como Pedro Sande recorrieron gran parte de los Andes Meridionales

1 Este trabajo fue publicado junto con el documento aludido, en los Boletines 2-3, del Centro de Documentación de la Universidad del Norte, en 1972. indagando personalmente información en una región que aún no se colonizaba fuertemente y donde, en consecuencia, la organización socioeconómica andina se mantenía poco alterada por la debilidad de los focos colonizadores españoles. Como esta carta describe especialmente particularidades del norte actual de Chile y de las regiones limítrofes, hemos creído conveniente transcribirla totalmente, ya que su texto completo se conoce apenas, como podría suponerse, y su utilización por parte de arqueólogos, antropólogos e historiadores puede ser positiva y múltiple.

Las materias que trata esta carta merecen que cada especialista obtenga sus propios comentarios, pero no cabe la menor duda que tanto arqueólogos, antropólogos, como etnohistoriadores verán con agrado cómo este documento verifica en gran medida la actual formulación teórica vigente sobre la organización de la sociedad andina en el momento de la invasión europea.

\section{Fuente bibliográfica}

La carta en cuestión apareció publicada completamente en el tomo II de Relaciones geográficas de Indias, publicadas por el Ministerio de Fomento-Perú, en Madrid 1885, en el apéndice $n^{\circ}$ III, págs. XXI a XXVIII; edición de cuatro volúmenes (1881-1897), bajo la dirección y prólogo de Marcos Jiménez de la Espada.

Posteriormente estas Relaciones geográficas de Indias fueron nuevamente editadas con un estudio preliminar de José Urbano Martínez Carreras, a cargo de ediciones Atlas, en Madrid 1965, y conforman los tomos 183, 184 y 185 de la Biblioteca de Autores Españoles (continuación). En esta edición el documento de Lozano Machuca está transcrito en el tomo 184, págs. 59 a 63.

En varias publicaciones relacionadas con las ciencias sociales antes referidas se ha hecho mención de este documento o se han copiado citas muy parciales. 
El primer autor logró obtener, en el año 1970, en España -donde actuó en comisión de servicios como historiador-investigador- una fotocopia del documento total, además de transcribir la carta fielmente del manuscrito 3040 (anteriormente: Ms J 58) de la Biblioteca Nacional de Madrid. El documento fue transcrito con ortografía y puntuación modernas y en esta forma también lo publicamos en los Boletines 2-3, del Centro de Documentación de la Universidad del Norte, en 1982.

Es importante destacar que el primer autor no encontró grandes diferencias entre el documento publicado y el manuscrito. Sin embargo, en ambas transcripciones íntegras -nos referimos a la transcripción del documento en Relaciones geográficas de Indias y en el tomo 184 de la Biblioteca de Autores Españoles-aparece la siguiente nota: "Procedente de estas minas existe en el Gabinete de Historia Natural de Madrid [ahora Museo de Ciencias Naturales] un enorme grano de cobre nativo y en parte cristalizado. Pesa algunos quintales y fue obsequio del cónsul de España en Cobija, señor Insausti, a la comisión de naturalistas españoles que viajó por América durante los años de 1862 a 1865". Debemos añadir que de esta expedición formaba parte, muy destacada, el Sr. Marcos Jiménez de la Espada, autor de la nota transcrita. Casassas, en las observaciones que proporcionó a la carta del Factor de Potosí, señala que tuvo oportunidad de examinar esta muestra en el museo indicado, en noviembre de 1970 . No obstante, nada ha podido averiguar acerca del paradero de la muestra que, según el texto del documento (compara: pág. 145 del manuscrito 3040), llevaba al virrey el portador de la carta de Lozano Machuca, Diego Enríquez.

En la pág. 145 (vuelta) del manuscrito 3040, Lozano Machuca observa que hay en el "valle de Atacama y contorno de él lápiz azul y jaspe de colores diferentes y negros y amarillos, turquesas finas"... etc. Al respecto, Marcos Jiménez de la Espada incluyó la siguiente nota: "Según mi amigo el insigne americanista y geólogo señor W. Reiss, estas piedras no son las que Lozano creía, sino la sustancia volcánica denominada sodalita".
Además, Juan Lozano Machuca comunica en la carta (compara: pág. 146 del manuscrito 3040) al Virrey del Perú que Diego Enríquez le lleva "la pintura y discreción de toda esta tierra". Casassas, en sus observaciones, señala que esta "pintura" o mapa de las tierras mencionadas en el documento de Lozano Machuca, no aparece junto al manuscrito en la Biblioteca Nacional de Madrid y que no obtuvo ningún éxito en las diversas gestiones que intentó en su búsqueda.

La segunda autora agradece al historiador Casassas su autorización para publicar integralmente la carta del Factor de Potosí, más los datos bibliográficos correspondientes, proporcionados por él.

El Centro de Documentación posee en sus depósitos abundante documentación para los siglos XIX y XX, pero para la historia colonial del norte del país, como es obvio de suponer, no posee una documentación abundante. En este sentido los aportes de los historiadores Oscar Bermúdez y José María Casassas demuestran precisamente el interés por cubrir grandes vacíos en la investigación de la historia colonial. Es ésta otra de las razones para publicitar este documento en esta oportunidad. Siempre es conveniente difundir algunas fuentes del conocimiento que, a pesar de ser tan lejanas, están íntimamente ligadas con el destino socioeconómico de esta región. Cuando Pedro Sande recorre el interior de Iquique (1581), observa con admiración una obra de canalización de aguas que había estado realizando la administración incaica para regar la Pampa del Tamarugal con recursos de aguas procedentes del altiplano. En aquella época se paralizaron las faenas por la invasión europea y debió esperarse hasta nuestros últimos años en que el río Lauca cumplió similar función. Es esta una de las lecciones más importantes que se desprenden de esta carta. El texto completo, aunque dos veces publicado, es de dificilísimo alcance, de modo que al transcribirlo en el Boletín referido creímos satisfacer muchas inquietudes en este sentido. 